\title{
Distributed Leadership, Trust and Online Communities
}

\author{
Jill Jameson ${ }^{1}$, \\ 1 The University of Greenwich, School of Education and Training, Mansion House, Bexley Road, Greenwich, London, SE9 \\ 2PQ, United Kingdom j.jameson@gre.ac.uk
}

\begin{abstract}
This paper analyses the role of distributed leadership and trust in online communities. The team-based informal ethos of online collaboration requires a different kind of leadership from that in formal positional hierarchies. Such leadership may be more flexible and sophisticated, capable of encompassing ambiguity and rapid change. Online leaders need to be partially invisible, delegating power and distributing tasks. Yet, simultaneously, online communities are facilitated by the high visibility and subtle control of expert leaders. This paradox: that leaders need to be both highly visible and invisible as appropriate, was derived from prior research and tested in the analysis of online community discussions using a pattern-matching process. It is argued that both leader visibility and invisibility are important for the facilitation of trusting collaboration via distributed leadership. Advanced leadership responses to complex situations in online communities foster positive group interaction and decision-making, facilitated through active distribution of specific tasks.
\end{abstract}

Keywords: Distributed leadership, online communities, paradox, visibility, invisibility, e-learning, case study, patternmatching, ambiguity.

\section{Introduction}

Positional leaders who are capable of sharing some powers encompassed within their role to delegate discretionary authority to others could be described as facilitators of a 'distribution' of leadership tasks. Yet the extent to which leadership authority can be shared or delegated is complex and situation-specific. Effective distribution of leadership requires high levels of trust between leaders and 'followers', but such trust is vulnerable to erosion in both face-toface and online communities. In more traditional analyses of power relations, highly conspicuous leadership builds trust, as 'visibility' is often regarded as a necessary attribute of power. In recent online communities, however, trends have shifted towards greater team collaboration and the high visibility of members rather than and/or alongside leadership. Hence leaders of online communities need to balance ongoing situational requirements for both visibility and invisibility, for outspokenness and silence, to enable greater agency and freedom to flourish in other participants' contributions. This paradox: that leaders of online communities need to be both highly visible and also invisible or 'hands-off' when necessary to facilitate the establishment of trust, emerged from reflections on prior research on leadership and trust (Jameson, 2009; Jameson and Andrews, 2008).

This paper argues that online communities benefit from flexible, low-key distributed team leadership in a practitioner-focused ethos of equality, in which competition is minimalised and communities of practice are supported (Wenger, 1998). This avoids top-down micro-managerial hierarchical control by managers, characterised by critics as interventionary 'new managerialism', in which reductive performativity reduces trust (Ball, 2003). Prior literature demonstrates that humility, humour and 'bottom up' practitioner empowerment can be stimulated through 'relational intelligence' intentionally fostered by the leaders of such communities. It has also been found that creative willingness to share leadership tasks and responsibilities in a distributed-coordinated team model enables successful teamwork (Jameson, Ferrell, Kelly, Walker and Ryan, 2006). To examine this, there is a need to consider distributed leadership as a response to situational complexity.

\subsection{Distributed leadership and complexity}

Distributed leadership has been substantially on the rise, in theory, for some years. Shared adaptive interactive group leadership approaches, inherent in the concept of distributed leadership, tend to be characterised as agile 'nonmanagement' and de-centralisation, as the concept of 'management' has become less popular and 'leadership' has assumed greater dominance. Simultaneously, such approaches encompass a relative downplaying of authority in 
structural hierarchies. Hartley noted (2007) that: 'Distributed leadership has currency: its time has come; it is the "new kid on the block' ... 'in vogue', attracting 'growing attention'... Since Gronn's preliminary taxonomy of distributed leadership... it has turned into something of a social movement.' [7] It seems that leaders who 'downplay' seniority to render some aspects of leadership authority invisible and allocate power to others in subordinate positions are those who enable distributed leadership. Such approaches elicit more willing grassroots support for innovations from staff than attempts by managers to enforce change through positional power. A drift towards the validation of 'softer' leadership approaches fostering social-emotional trust in communities has occurred, in contrast to rational 'management' via positional structures, as Hartley notes:

'Biggart (1989) concludes that firms can no longer control workers through rational-legal (that is, bureaucratic) structures: "Independent work that relies on solidarity, respect, or mutual trust, is poorly served by bureaucratic structures that create authority differences"... The slippage from management to leadership since 1989 ... resonated with an increasingly premodern atavistic tendency .... towards communities whose basis is an appeal to the nonrational.... a recent MORI poll.... noted a 'drifting from [the] rational to polysensuality'...[an] emotional turn ... also ... seen in educational management.' [7]: 208

Arguably, highly advanced leadership skills are needed to respond to the complexities of online interactive community leadership tasks when power is now more distributed, the informal non-rational 'emotional turn' identified by Hartley is evident, and yet, simultaneously, management control systems are still required. Prior leadership researchers have analysed the concept of paradoxical demands in complex leadership situations (Denison, Hooijberg and Quinn, 1995; Handy, 1994; Lewis, 2000; Lips-Wiersma, 2004), while others recognize dualistic and contradictory challenges facing leadership that must be balanced, challenged or transcended for leadership to be effective. Denison, Hooijberg and Quinn (1995) reflect that the:

'test of a first-rate leader may be the ability to exhibit contrary or opposing behaviors (as appropriate or necessary) while still retaining some measure of integrity, credibility, and direction. Thus, effective leaders are those who have the cognitive and behavioral complexity to respond appropriately to a wide range of situations that may in fact require contrary or opposing behaviors.' [5]: 526

Encompassing the seemingly contradictory demands of paradoxical situations is increasingly a requirement for leadership within the shifting, casual, ambiguous complexities of online communication in social networking sites. Such communities make specific kinds of continuously evolving demands on leadership. The team-based informal ethos of online collaboration requires a different kind of leadership - more flexible, sophisticated, capable of encompassing both ambiguity and rapid change - from that practised in formal face-to-face positional hierarchies in institutions. The apparently contradictory requirements of online environments: i.e. that leaders need to be both strongly visible and also to step back into silent invisibility, to be both informally friendly and also sometimes formal and controlling, to be both an innovator and a monitor of online behaviour, means that the effective leadership of such communities is no easy task. The reconciliation of apparently contradictory opposites requires an ability to encompass both paradoxical thinking and rapidly responsive social interaction, in coping with fast-moving pace of online sites. As Denison et al. observe, defining the need for behavioural complexity to cope with diverse multi-faceted situations, 'leaders with a broad behavioral repertoire and the ability, as a part of that repertoire, to perform roles that include a degree of contradiction or paradox, will be the most effective.' [5]

\subsection{Online communities}

Online communities have massively grown in number during the past decade, developing a large global membership. Simultaneously, online communication processes have become demanding, requiring advanced leadership of online networks. Many web users have also developed into sophisticated, expert online contributors. For example, although only founded in 2004, Facebook is now the second largest social networking facility in the world, with 175 million active community users. The Facebook Factsheet notes in its statistics page that 'more than 3 billion minutes are spent on Facebook each day (worldwide)' [6].

In 2004, Plant had defined online communities as "a collective group of entities, individuals or organizations that come together either temporarily or permanently through an electronic medium to interact in a common problem or interest space" [16]. He recorded an estimated 400,000 online communities (ibid., 2004). More recently, social network growth has massively accelerated: by the end of 2007 active memberships of 230m+ individuals participating worldwide in social network sites were recorded, although this was expected to flatten out by 2012 (Datamonitor, 2007). Amongst these online communities there exist countless numbers of social networking sites. As defined by Boyd and Ellison (2007), such sites comprise 'web-based services that allow individuals to (1) construct a public or semi-public profile within a bounded system, (2) articulate a list of other users with whom they share a 
connection, and (3) view and traverse their list of connections and those made by others within the system.' [2]: 1

Online community sites increased their monitoring and control systems in response to early user problems and scandals. Given potential problems with regulation and safety in online communities, requirements for online leadership via facilitation have begun to be specified, for example, in online learning sites (Salmon, 2000). Crawford (2000) notes that facilitation of online communities is now an essential requirement:

'The facilitator is absolutely indispensable. There needs to be somebody 'who knows' and who has a role as leader to take participants gently into the community and make them feel welcome-part of the community. They need to be obviously keen on the system and dedicated to making it work. An enthusiast.' [3]: 441

Assuring effective leadership in online communities is an important prerequisite for safe, harmonious participation by members. Such leadership seems best achieved through distributed power sharing that encourages trust and copes with apparently contradictory requirements for visibility and invisibility, as this paper proposes.

\section{Methodology}

A qualitative analysis was carried out to investigate the ways in which distributed leadership and trust are linked with paradoxical requirements regarding the visibility of leadership in online communities. During evaluation of the eLIDA CAMEL project (2006-07), an hypothesis emerged that a visibility/ invisibility leadership paradox existed regarding online interactions: i.e. that leaders need to be both absent and present for effective discussion management. To test this, three case studies of online community interactive discussions were collected and analysed, as reported in Jameson (2009). The hypothesis was tested in the analysis of random case study conversation threads from an online charitable social networking site, pseudonymously named FLOS. An analysis of asynchronous conversational interaction in the online polylogues created amongst members and leaders in the social networking site was carried out, using a case study 'pattern-matching' methodology to analyse conversation threads. This was devised from a replication of Lambe's (2006) work on the analysis of conflict in online communities, in consideration also of the work of Marcoccia (2004) in analysing written conversation in online newsgroup polylogues. Following the analysis of conversation patterns in threads of online messages for the presence and absence of distributed leadership, a synthesis of the summary textual findings was reported and recommendations for fostering improved distributed leadership in online communities were suggested.

\section{Findings}

The analysis of case studies produced by the JISC-funded eLIDA CAMEL design for learning team (Jameson, 2008) led to the hypothesis that a 'visibility paradox' operates regarding the effectiveness of distributed leadership in online communities. Observations about relational intelligence, visibility and invisibility were tested in the analysis of several online community discussions. These are explored in Jameson (2009) and in the current paper, which reports selected findings from the analysis of case study conversational threads between members of online communities, as illustrated in Figure 1. Three randomly selected online community case study discussions were recorded and analysed from a global social networking site.

\subsection{Three case study discussions from an online community site}

Case Study 1 on Effective Leadership: Kipper, one of the social network site hosts, opened up a discussion about a site innovation. This discussion comprised 69 posts over eight days. Kipper's announcement was positively received, with neutral comments and a few critical posts. Mary and Laura, two other leaders, commented helpfully on Days 5 and 7, receiving positive and neutral replies, followed by a new post (from Eve) with an extended criticism. One of the discussion group sub-leaders (Jean) did not react well to Eve's criticism, posting two inscrutable emoticons. Eve's reaction was swift - she replied to say, 'Again a deafening silence on valid issues. The emoticons is [sic] out of place and frankly rude'. Another member agreed with Eve's criticism. Jean replied that the emoticons had been meant as a criticism of site leaders. Kipper replied to Jean's criticism, thanking her for feedback, re-stating the purposes of the site and talking about new initiatives. Kipper then said she 'didn't mean to hijack this thread, so I'm starting a new one to solicit this type of feedback. Please join the conversation: new thread address...' Following this, neutral and positive posts were posted, with one further criticism. Kipper welcomed the critical feedback, providing information and joking about deficits, saying 'Thank you again for this valuable feedback. We will look into ways we can 
improve this feature'. Sub-group leader Jean replied politely. Lynne thanked Kipper as group leader. The final message rounding off the discussion was by Mary, another site leader, who welcomed the thread to discuss feedback, introducing new aspects of work to respond to various criticisms. Overall, this first case study provided an example of a relatively effective balance of visibility and invisibility on the part of the main leader, with task distribution operating flexibly via other leaders and members.

Case Study 2 on Aggression and Leadership Neglect: An ordinary site member, Gerald, set up and opened this 111post three-day thread as discussion group leader, making an announcement alerting site members to a technical problem. This was greeted with alarm and thanks, Day 1 posts remaining neutral and positive. During Day 2, however, the discussion took a critical, negative turn. A lack of leader information (4\% or four posts), combined with Gerald's low visibility, meant an increasing number of critical posts received no monitoring or response. Three Day 2 information posts from Gerald addressed technical issues with a hectoring tone. Gerald reminded members that 'when I post Virus Alerts then it is not personal...' However, he did not reply to critical comments and, following a fifth information post, did not enter the conversation again, simply leaving other members to get on with it. As a result of leadership neglect, conversation on Day 3 took a negative turn, with aggressive, insulting responses (5\% or five posts) introduced. A lack of visible presence from Gerald as discussion group leader meant that, as in the online conflict
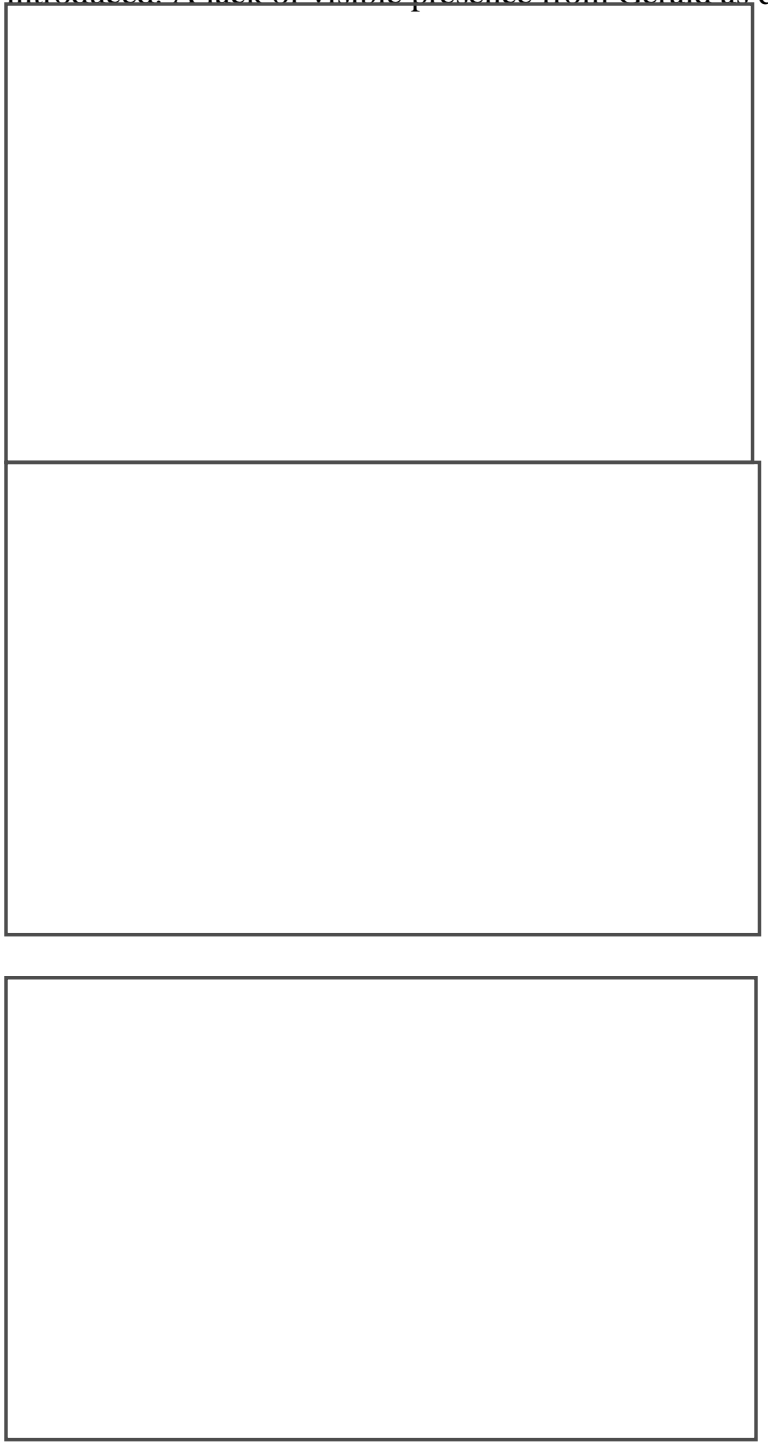

Fig. 1. Analysis of types and numbers of postings in three online community discussions

analysed by Lambe (2006), members tried to compensate for others' insulting remarks. Reflective comments by Wolf were posted in response to the squabble: 'It never fails, it always seems that no matter what topic there always seems to be an argument over something or someone coming in making nasty remarks about something that has nothing to 
do with the topic at hand.' These reflections were followed by defensive explanations and further personal criticisms. The relative decline in the atmosphere of the discussion reflected a lack of leadership visibility. Overall, this second case study is an example of an ineffective balance of visibility and invisibility by Gerald, who provided low levels of support. Critical feedback and aggression remained unanswered. The emergence of aggressive comment stimulated moderating input from ordinary members, who kept discussions in check in the absence of leadership. 'Distributed leadership' arose naturally from within the group in a default 'crisis management' situation, being neither organized nor supported by Gerald, whose leadership was both neglectful and ineffective.

Case Study 3: Aggression, Defection and Leadership Rescue: An ordinary site member, Barbara, set up and opened this 86-post eight day discussion involving 15 participants. As discussion group leader, Barbara alerted members to spam and asked for action. Her announcement attracted agreement and discussions were initially neutral. However, during Day 1, a more critical exchange emerged that degenerated into serious name-calling and insults. On Day 2, Justine posted an emoticon to say members should restrain themselves. Dragon wrote to chastise aggressive responses. Neutral comment was followed by further aggression. On Day 3, T-Rex advised: 'If someone's post is not to your liking, ignore it! Why do we have to constantly degenerate into personal attacks that serve no purpose at all sometimes it's like watching kids in a playground...' After neutral comments, Day 3 ended on a positive note. On Day 4, group leader Kipper noted that 'when you encounter inappropriate behaviour... members should flag this'. Barbara thanked Kipper, but could not resist a further aggressive swipe at Bacon. Positive and neutral comments followed. Days 5-8 witnessed no further aggression as Kipper provided further information. No further exchanges followed until a final positive post on Day 8, by Sheila, a new member. Overall, this third case study provided an example of a 'leadership rescue', in which aggression was followed by leadership intervention. Barbara provided low levels of group leadership support, resorting to name calling even when supported by Kipper. Following much community aggression, Kipper's interventions as a main site leader restored the balance of leadership visibility, following which all hostility stopped.

\section{Discussion}

There is as yet no agreed definition about the practice of distributed leadership. As Hartley has observed: 'the research evidence which informs distributed leadership is not yet well founded.' [7]: 206-10. Yet there is growing evidence that distributed leadership exists to an extent in online communities and is best achieved when leaders honestly outline the extent of 'distribution' and collaborate also as team members.

The case study analysis found that both high visibility and invisibility of leaders in online communities were needed to ensure proactive social exchange. Three randomly selected group conversations involving a range of members were analysed for the presence and absence of leaders within a distributed leadership model. The analysis found that leadership was variably distributed between several site host members, sub-leaders and members of discussion groups, as illustrated in Figure 1.

The interactive thread in case study one was analysed to assess the pattern of leader and member posts. Analysis revealed that although there was a relatively high level of critical feedback ( $23 \%$ or 16 posts) there was also a high level of leader information (19\%, or 13 posts), with good visibility from the main leader and other leaders who came in to support her in subtle ways. An odd post by Jean, sub-group leader ('leader inscrutability' $3 \%$ or 2 posts) contained two critical emoticons, both hard to understand and critical of site leaders. These attracted critical comment, though the group focus was pulled back into line through Kipper's intervention as overall leader. An effective balance between leadership visibility and invisibility occurred: the leader was present, but stepped back to enable the group to engage in discursive interaction.

In case studies two and three, leadership balance was much less effective, as insufficient levels of leader visibility were achieved. In case study two, the group discussion leader neglected to cultivate relational intelligence between members and the discussion degenerated to include an unhelpful degree of critical comment (28\% or 31 posts) and aggressive behaviour (5\% or five posts), with leader information levels being relatively low (4\%, or four posts), focused only on discussion content and not on social interaction. In case study three, an example of a highly aggressive series of interactions, a lack of leadership information and presence in Days 1-3 was problematic, with a very high degree of critical comment (27\% or 23 posts) and aggressive behaviour ( $20 \%$ or 17 posts). In response to this dilemma, the leadership presence of Kipper on Days 4-5 mitigated growing levels of hostility. An effective series of information and interactions by Kipper, an agile positional leader, resulted in an improved situation, with overall leadership involvement ( $6 \%$ or five posts) reaching a relatively healthy balance by the end of debate on Day 8 . 
However, damage from the extremely negative aggressive interactions did have a lingering effect, as some members were still clearly upset by the end of the discussion.

High leader visibility was found to be beneficial, to provide information and promote relational intelligence for group cohesion. When leaders were involved in discussions, aggression between members diminished and they felt safer and happier in interactions. Many members expressed appreciation for leaders' efforts. There was little evidence of any critical attitude towards site leaders, with the exception of the 'inscrutable' emoticons posted by one sub-group leader. The moderating effect of leader visibility seemed to be welcomed and their presence in discussions appeared to have beneficial results. Leader responses were polite, informative, clear and brief, though full enough to be informative. Leaders signed off all posts with a polite greeting such as 'sincerely', plus their name and official role in the site.

However, it was clear from online discussions that participants also benefited from site leader absence from time to time, so that members could pursue discussions without feeling constantly 'watched'. The fact that two case study discussions were led by group discussion leaders who wanted to post up a new debate was a positive aspect of this site. This enabled ordinary members to lead discussions and have real ownership of debates in which they had a leading role. The distribution of leadership was therefore effected through site leader invisibility when such discussions emerged. To achieve the high degree of participation and involvement that this site routinely attracts, such occasional low visibility from site leaders seems to be a necessity.

When discussion leaders were either negligent or aggressive (as in studies two and three), there was a likelihood that members would post more belligerent responses, and that aggression would degenerate quickly into increasing hostility. One member compared this to the behaviour of 'kids in a playground'. When positional site leaders were around, such leaders either directly or indirectly stopped the name-calling that otherwise emerged within discussion threads. Effectively distributed leadership enabled members to achieve a balance between visibility and invisibility of 'presence' in online discussions. It seems that conscious adoption of distributed-coordinated team leadership for online community interaction may develop trust and enable genuine dialogue between team members at all levels in an online community. This can assist leaders to know when and how to engage with high visibility and when to subtly fade away while team activities and decision-making processes are underway.

This paper proposes that distributed leadership is an effective model of operation for the leadership of online communities. A visibility-invisibility paradox that emerged from a prior project was tested in the analysis of conversational interaction within three randomly selected discussion groups. It was found that both high visibility and invisibility are required of leadership when the occasion demands. Findings were that leadership was stronger in achieving positive results if site leaders with positional authority demonstrated a high degree of relational intelligence and humour, operating visibly to announce information and provide responses that firmly but subtly addressed problems, as in case study one. Conscious adoption of distributed-coordinated team leadership develops trust and enables genuine dialogue between team members at different levels in online communities. A tailored local combination of distributed leadership responses should be applied to dilemmas such as the emergence of aggression. Benefits of 'collaborative advantage' can accrue from an effectively managed culture of distribution if individuals are invited to lead key tasks. The process of online task distribution tends to transform communities into more inclusive groups through synergistic, dynamic processes of active engagement in leadership's vision and values. Informal practitioner leaders can be empowered with the knowledge, authority and problem-solving skills to manage complex situations.

It is recommended that leaders of online community discussions should demonstrate both high visibility and discretion in terms of the mission, purposes and control of group operations, but that they also should demonstrate an ability to 'step back' from time to time to enable others, including group members, to be responsible for group discussions. Clear demonstration of relational intelligence, sensitivity and informal, friendly responsiveness to group posts is an important requirement for leadership to foster trust amongst members. Leaders need also to be clear, unambiguous and supportive in salutations and information to members. The group benefits if leaders pick up quickly on emerging issues that could cause aggressive responses. The latter are most effectively handled using a consistently sensitive, friendly, informal approach that subtly and indirectly tackles the question of appropriate behaviour. 'Distributed leadership' can, if achieved effectively, transform communities by enabling everyone to be seen as a leader of a specialism, with 'collaborative advantage' accruing from synergetic group leadership. Effective leaders need to demonstrate relational intelligence, sensitivity and awareness regarding when and how to engage with high visibility and when subtly to fade away while member activities and decision-making processes are underway. It is 
recommended that further research is carried out to investigate appropriate methods for the operation of distributed leadership to build trust in online communities.

Acknowledgments. The author thanks the JISC for funding the eLIDA CAMEL project, the Centre for Excellence in Leadership/LSIS for research funds, and eLIDA CAMEL, eLISA and JISC infoNet CAMEL team partners, institutions and agencies.

\section{References}

1. Ball, S. The teacher's soul and the terrors of performativity, Journal of Education Policy, 18: 215-28. (2003)

2. Boyd, D. M., and Ellison, N. B. Social network sites: Definition, history, and scholarship. Journal of Computer-Mediated Communication, 13(1), article 11, (2007), accessed online 27th February, 2009: http://jcmc.indiana.edu/vol13/issue1/boyd.ellison.html

3. Crawford, M., Enhancing School Leadership: Evaluating the Use of Virtual Learning Communities, Educational Management Administration \& Leadership 30,4:431-45. (2002)

4. Datamonitor The future of social networking: Understanding market strategic and technological developments, New York: Technology Report, Datamonitor, (2001)

5. Denison, D.R., Hooijberg, R. \& Quinn, R.E.: Paradox \& Performance: Toward a Theory of Behavioral Complexity in Managerial Leadership, Organization Science, 6,5:524-40 (1995)

6. Facebook Factsheet available online at Facebook, accessed 27th February 2009 at: http://www.facebook.com/press/info.php?statistics\#/press/info.php?factsheet

7. Hartley, D. The Emergence of Distributed Leadership in Education: Why Now? British Journal of Educational Studies, 55, 2: 202-214. (2007)

8. Jameson, J. The eLIDA CAMEL Model of Collaborative partnership: A Community of Practice in Design for Learning, Third International Conference on e-Learning (2008).

9. Jameson, J. and Andrews, M. Trust and Leadership in the Learning and Skills Sector, CEL Research Report, Centre for Excellence in Leadership: Lancaster University. (2008)

10. Jameson, J. Distributed Leadership and the Visibility/Invisibility Paradox in Online Communities, Human Technology Journal: Special Issue (forthcoming, 2009)

11. Jameson, J., Ferrell, G., Kelly, J., Walker, S. and Ryan, M. Building trust and shared knowledge in communities of e-learning practice: collaborative leadership in the JISC eLISA and CAMEL lifelong learning projects. BJET, 37, 6: 949-968. (2006)

12. Lambe, P. Conflict, Gender and Identity in Online Communities, (2006) online article at: http://www.greenchameleon.com/ accessed December 15th, 2008.

13. Handy, C.: The empty raincoat, making sense of the future. Arrow Books, London (1994)

14. Lewis, M.W.: Exploring Paradox: Toward a More Comprehensive Guide, The Academy of Management Review, 25, 4: 760776, 2000),

15. Lips-Wiersma, M.: Furthering Management and Spirituality Education through the Use of Paradox - Journal of Management Education, 28: 119-133 (2004).

16. Plant, R., Online Communities, Technology in Society, 26,1:51-65 (2004)

17. Salmon, G. (2000) E-Moderating: The Key to Teaching and Learning Online. London: Kogan Page.

18. Wenger, E. (1998) Communities of Practice, Cambridge: Cambridge University Press. 